\title{
Geochemical Characteristics of Jurassic Coal Derived Gas in Northwest China
}

\author{
HAO AISHENG $^{12}$, GUO JIANYING ${ }^{12}$, Li JIAN ${ }^{12}$, RAN QIGUI ${ }^{12}$, \\ QI XUENING ${ }^{12}$ \\ ${ }^{1}$ Research Institute of Petroleum Exploration \& Development, \\ ${ }^{2} \mathrm{Key}$ \\ PetroChina, Beijing 100083, China \\ Laboratory of Gas Reservoir Formation and Development, \\ CNPC, Langfang 065007, China
}

Jurassic coal-measure strata are widely developed in Northwest China, mainly distributed in the Tarim Basin, Junggar Basin, Qaidam Basin and Turpan-Hami Basin. Although the climate and sedimentary environment of Northwest China were similar during Jurassic period, the characteristics of coal-formed gas in Northwest China vary greatly due to the differences of tectonic movement, sedimentary and evolutionary characteristics during later period. Based on the data of hydrocarbon generation characteristics, gas composition and carbon isotope of Jurassic source rocks, the geochemical characteristics of Jurassic coal derived gas in Northwest China are comprehensively compared and analyzed.

The drying coefficient of Jurassic coal-formed gas in Western China shows different types: the main type of Jurassic coal-formed gas in the Turpan-Hami Basin is wet gas, that in the Qaidam Basin is mainly dry gas, that in the Kuqa Depression of the Tarim Basin and the Junggar Basin has wide range of drying coefficient. Carbon isotope values of Jurassic coal-derived methane in Northwest China have wider range $\left(\delta^{13} \mathrm{C}_{1}:-48.4 \%\right.$ to $\left.-25 \%\right)$ : that in the Turpan-Hami Basin is low (mainly $-45 \%$ to $-36.4 \%$ ), that in the Junggar Basin has wide range (mainly between $-48.4 \%$ to $-25.6 \%$ ); that in the Qaidam Basin is heavy (mainly $-38.5 \%$ to $-26 \%$ ); that in the Kuqa Depression is heavy (mainly $-38.9 \%$ o to $28 \%$ ). Carbon isotope of coal-formed gas in Northwest China is positively correlated with carbon isotope of methane; $\delta^{13} \mathrm{C}_{2}-\delta^{13} \mathrm{C}_{1}$ has big variation scope, and is negatively correlated with carbon isotope of methane. The carbon isotope of coal-derived gas in Northwest China is generally a positive carbon isotope series, partly with $\mathrm{C}_{2}-\mathrm{C}_{3}$ inversion. Based on experimental data, the coal derived gas at low mature to early mature stage in Northwest China mainly generated from coal-measure mudstone. Maturity is the main reason for the great difference of Jurassic coal derived gas in Northwest China, and mixture of gases is also another important factor. 